\title{
ESCALAS ESPECÍFICAS PARA MEDIR A INFRAESTRUTURA ESCOLAR DA EDUCAÇÃO BÁSICA
}

\section{Joaquim José Soares Neto'}

Elianice Silva Castro ${ }^{2}$

${ }^{1}$ Professor Titular do Programa de Pós-Graduação em Desenvolvimento, Sociedade e Cooperação Internacional do Centro de Estudos Avançados Multidisciplinares (Ceam) e no Mestrado Nacional Profissional em Ensino de Física da Universidade de Brasília (UnB), Brasília, Distrito Federal, Brasil. E-mail: jjsoaresneto@gmail.com.

${ }^{2}$ Doutora em Desenvolvimento, Sociedade e Cooperação Internacional pela Universidade de Brasília, Brasília, Distrito Federal, Brasil. E-mail: elianice.castro@gmail.com. 


\section{Resumo}

A fim de orientar políticas públicas de investimento para educação básica brasileira, este estudo propõe escalas de infraestrutura específicas para cada um dos segmentos de ensino, identificando uma infraestrutura mínima a cada um desses ambientes escolares. Foram definidas constitutivamente e operacionalmente as características da infraestrutura escolar de segmento de ensino; estimados os parâmetros dos itens; definidos e descritos os níveis e das escalas e realizadas análises descritivas.

Palavras-chave: Infraestrutura escolar. Educação básica. Indicadores educacionais.

\section{Abstract}

In order to guide public investment policies for Brazilian basic education, this study aimed to propose three specific school infrastructure scales for each of the education segments, identifying a minimum infrastructure for each of these school environments. Thus, the infrastructure of each segment was constitutively and operationally defined; estimation of item parameters; definition of levels and description of scales and descriptive analysis.

Keywords: School infrastructure. Basic education. Educational indexes. 


\section{INTRODUÇÃO}

A igualdade e equidade constituem um dos eixos de pesquisa na área de eficácia escolar e, conforme Reynolds et al. (2014), existe uma tendência internacional em associar a eficácia de sistemas educacionais à qualidade em educação. Nesse sentido, a eficácia escolar, ao englobar qualidade e equidade, compreende o quanto o desempenho de uma escola é melhor do que o de outras e o quanto a escola é capaz de compensar as diferenças de entrada dos estudantes (SAMMONS, 1995; REYNOLDS et al., 2014).

No Brasil, as pesquisas sobre eficácia escolar também se orientam pela perspectiva de análise da igualdade e da equidade, com o objetivo de identificar variáveis do nível da escola que diminuam a interferência de variáveis do nível do estudante nos resultados escolares. Por essência, essas pesquisas buscam compreender como as diferenças de entrada dos estudantes, relacionadas a gênero, etnia e nível socioeconômico, e as diferenças de recursos e dos processos escolares - infraestrutura escolar, formação de professores e gestão escolar - podem influenciar no desempenho e na diminuição das desigualdades educacionais (ALBANEZ et al., 2002; ANDRADE et al., 2003; SOARES; ALVES, 2003; SOARES, 2004; SOARES; ANDRADE, 2003; CASTRO, 2014; KARINO, 2016). Via de regra, os resultados desses estudos indicam que os fatores que geram eficácia escolar têm contribuído para o aumento das desigualdades no que se refere ao desempenho dos diferentes grupos de estudantes.

A fim de contribuir com a identificação desses níveis de desigualdade, especificamente no que se refere aos recursos escolares do país, Neto et al. (2013) propuseram um indicador capaz de aferir a infraestrutura escolar da educação básica brasileira. Nessa escala da infraestrutura, que foi subdividida em quatro níveis (elementar, básica, adequada e avançada), todas as escolas receberam um "score" interpretável e que expressa um significado prático e objetivo do que constitui a sua infraestrutura escolar. Esse estudo, além de inovar ao interpretar os níveis de infraestrutura escolar do país, apresentou como resultado indícios de grande desigualdade de recursos entre as escolas, especialmente entre aquelas localizadas nas zonas rurais e nas regiões Norte e Nordeste (NETO et al., 2013).

Esse indicador subsidiou outros estudos que também buscavam avaliar a influência da infraestrutura sobre o desempenho e no aumento das desigualdades. Castro (2014) utilizou a escala de infraestrutura escolar como uma das variáveis de processo associada ao desempenho e identificou que escolas que possuem nível socioeconômico baixo e naquelas em que, mais de $80 \%$ 
dos estudantes atendidos são beneficiários do Programa Bolsa Família (PBF), a infraestrutura e o nível de escolaridade do docente exercem o mesmo nível de influência no desempenho dos estudantes. Em contrapartida, em escolas cujo percentual de estudantes beneficiários do programa é de apenas 20\%, a infraestrutura tem um poder de influência no desempenho escolar muito maior em relação à formação docente, mas similar em relação ao nível socioeconômico. Nessa mesma linha de investigação, Karino (2016) verificou que a chance de sucesso acadêmico de um estudante pobre é de aproximadamente um terço da chance de um estudante de outro nível socioeconômico.

A fim de subsidiar uma investigação nesse campo, Castro, Karino e Neto (2018, no prelo) analisaram a série histórica da escala de infraestrutura escolar, no espaço de tempo compreendido entre 2007 e 2017. Um dos resultados apresentados é o inexpressivo aumento de 0,8\% de escolas da educação básica com infraestrutura escolar adequada nesses onze anos, nível representado por apenas $21,4 \%$ das escolas do país em 2017. As escolas adequadas são caracterizadas pela existência de espaços como sala de professores, biblioteca, laboratório de informática e sanitário para Educação Infantil (El), quadra esportiva e parque infantil, além de possuírem equipamentos complementares, como copiadora e acesso à internet.

Os autores apontam a necessidade de novos indicadores que considerem as especificidades dos itens para cada um dos segmentos de ensino da educação básica, pois a atual escala parte do pressuposto de que todas as variáveis $^{3}$ possuem a mesma adequabilidade para todos os segmentos. Todavia, verificam-se possíveis desajustes entre a relevância dos itens e o nível de dificuldade na composição da escala de infraestrutura escolar, quando eles são analisados em consonância com o seu posicionamento. Em outras palavras, itens que caracterizam escolas com infraestrutura adequada, por exemplo, não necessariamente são representativos para todos os segmentos de ensino. Essa constatação indica, sobretudo, uma limitação para a movimentação das escolas na escala de infraestrutura escolar, considerando o princípio da cumulatividade pressuposto pela Teoria de Resposta ao Item (TRI). Nesse indicador, observa-se que a viabilidade de movimentação pode estar relacionada muito mais ao segmento de ensino que as escolas oferecem do que ao traço latente observado, que são os itens que compõem a sua infraestrutura.

No intuito de superar essa barreira, o presente estudo propõe três indicadores de infraestrutura escolar, específicos para cada um dos segmentos da educa-

\footnotetext{
${ }^{3}$ Das 34 variáveis inicialmente consideradas, cinco foram submetidas a um tratamento diferenciado: parque infantil, sanitário para El e berçário (somente para escolas que ofertam El); laboratório de ciências (somente para as escolas que ofertam Ensinos Fundamental e Médio); e cozinha (somente para as escolas públicas, uma vez que nelas a alimentação escolar é obrigatória). Para as escolas às quais essas variáveis não se adequavam, estas foram tratadas nas análises da TRI como "não se aplica".
} 
ção básica (El, Ensino Fundamental - EF e Ensino Médio - EM), construídos com base no princípio da validade das medidas e focando especificamente nas evidências, com base no conteúdo, que definem o traço latente observado. O enfoque dado às evidências de validade dos indicadores propostos faz-se necessário diante da necessidade de verificar se as medidas por eles produzidas constituem uma representação adequada do construto mensurado, apontando se esse conceito está sendo representado por todas as suas definições constitutiva e operacional.

Assim, pretende-se identificar a especificidade do conceito infraestrutura escolar com base em teorias que sustentem as escalas específicas para cada um dos segmentos de ensino, superando a perspectiva até então estabelecida de que a infraestrutura é fundamentada exclusivamente por variáveis operacionais e pelas medidas produzidas por indicadores, fazendo com que a definição constitutiva do conceito seja mais ampla do que sua definição operacional. De posse dessas ferramentas, pretende-se identificar e mensurar as desigualdades e inequidades na infraestrutura escolar para o El, o EF e o EM. Este estudo ainda objetiva verificar as diferenças dos níveis de infraestrutura dos diferentes segmentos de ensino da educação básica e demonstrar os problemas de equidade a que estão expostos os estudantes que têm acesso a escolas com poucos recursos.

Método

A análise dos dados para a construção dos indicadores de infraestrutura escolar de cada um dos segmentos de ensino da educação básica ocorreu em quatro etapas: (1) definição constitutiva e operacional da infraestrutura escolar e tratamento das variáveis, considerando a sua pertinência para cada um dos segmentos; (2) estimação dos parâmetros dos itens para cada segmento, por meio do Modelo de Respostas Graduais (MRG) da TRI, utilizando os bancos do Censo Escolar de 2017; (3) definição e descrição das escalas de infraestrutura escolar para a El, o EF e o EM; e (4) análise descritiva para cada uma das escalas, considerando a região, a dependência administrativa e a localização das escolas de cada um dos segmentos de ensino.

Definição constitutiva e operacional da infraestrutura escolar e tratamento das variáveis

A literatura indica que o conceito de infraestrutura, de modo mais amplo, está associado ao locus privilegiado do processo educacional de transmissão de valores culturais e conhecimentos historicamente constituídos, independentemente se sua estrutura é planejada e adequada ou um espaço adaptado (SASTRE, 2010). No presente estudo, o conceito de infraestrutura escolar será 
compreendido, de modo constitutivo, enquanto a materialidade da escola, o prédio e os recursos e materiais disponíveis na instituição escolar (KOWALTOWSKI, 2011). Para a sua definição operacional, será considerada a matriz de especificação da infraestrutura escolar, apresentada no Quadro 1, composta por cinco fatores estruturais: infraestrutura básica; infraestrutura pedagógica, infraestrutura predial; equipamentos de apoio pedagógico; e adequação a necessidades especiais (CASTRO, 2018,no prelo).

Quadro 1 - Matriz de especificação da infraestrutura escolar

\begin{tabular}{|c|c|}
\hline Variáveis do censo escolar & Definição do conceito (referencial teórico) \\
\hline \multicolumn{2}{|l|}{ INFRAESTRUTURA BÁSICA } \\
\hline $\begin{array}{l}\text { Abastecimento de água } \\
\text { Abastecimento de energia elétrica } \\
\text { Esgoto sanitário } \\
\text { Sanitários }\end{array}$ & $\begin{array}{l}\text { Conexão da infraestrutura das escolas com serviços públicos básicos } \\
\text { (eletricidade, água potável, sanitários, esgoto, sanitário dentro ou fora } \\
\text { do prédio escolar etc.) (SÁTYRO; SOARES, 2007; DUARTE; GARGIULO; } \\
\text { MORENO, 2011). } \\
\text { Tipo de escola (pública ou privada) (CERQUEIRA; SAWYER, 2007). } \\
\text { Tipo de escola (rural ou urbana) (NETO et al., 2013). } \\
\text { Condições e instalações físicas das escolas (UNESCO; LLECE, 2008; } \\
\text { JESUS; LAROS, 2004; DALLAGNOL, 2015). } \\
\text { Prédios e instalações adequados (SOARES; 2007). }\end{array}$ \\
\hline \multicolumn{2}{|l|}{ INFRAESTRUTURA PEDAGÓGICA } \\
\hline $\begin{array}{l}\text { Quadra esportiva } \\
\text { Sala de leitura/biblioteca } \\
\text { Laboratório de ciências } \\
\text { Laboratório de informática }\end{array}$ & $\begin{array}{l}\text { Áreas acadêmicas e pedagógicas (DUARTE; GARGIULO; MORENO, 2011). } \\
\text { Dependências/benfeitorias (SÁTYRO; SOARES, 2007). } \\
\text { Disponibilidade de espaços educativos e de atividades recreativas, } \\
\text { desportivas e áreas de usos múltiplos (ginásio, auditório, quadra) (DUARTE; } \\
\text { GARGIULO; MORENO, 2011; SÁ; WERLE, 2017). } \\
\text { Recursos escolares (FLETCHER, 1998). } \\
\text { Qualidade da infraestrutura escolar básica e do espaço físico (EI/EF) (MOTA, } \\
\text { 2012). } \\
\text { Infraestrutura, gestão escolar e desempenho em leitura e matemática } \\
\text { (LIMA, 2012). }\end{array}$ \\
\hline \multicolumn{2}{|l|}{ INFRAESTRUTURA PREDIAL } \\
\hline $\begin{array}{l}\text { Sala da diretoria } \\
\text { Sala de professores } \\
\text { Cozinha } \\
\text { Área verde }\end{array}$ & $\begin{array}{l}\text { Recursos tecno-pedagógicos (JESUS; LAROS, 2004). } \\
\text { Áreas acadêmicas e pedagógicas (DUARTE; GARGIULO; MORENO, 2011). } \\
\text { Dependências/benfeitorias (SÁTYRO; SOARES, 2007). }\end{array}$ \\
\hline \multicolumn{2}{|c|}{ INFRAESTRUTURA PARA EQUIPAMENTOS DE APOIO PEDAGÓGICO } \\
\hline $\begin{array}{l}\text { Projetor multimídia (datashow) } \\
\text { TV } \\
\text { DVD } \\
\text { Computador } \\
\text { Aparelho de som } \\
\text { Acesso à internet } \\
\text { Impressora } \\
\text { Copiadora } \\
\text { Antena parabólica }\end{array}$ & $\begin{array}{l}\text { Infraestrutura tecnológica (SÁ; WERLE, 2017). } \\
\text { Inserção de novas práticas pedagógicas (ALLAN, 2011; ASSIS, 2011; } \\
\text { CZESZAK, 2011; MENEZES, 2011). }\end{array}$ \\
\hline \multicolumn{2}{|c|}{ INFRAESTRUTURA ADEQUADA ÀS NECESSIDADES ESPECIAIS } \\
\hline $\begin{array}{l}\text { Sala para atendimento especial } \\
\text { Banheiro para Portadores de Necessidade } \\
\text { Especiais (PNE) } \\
\text { Dependências PNE }\end{array}$ & $\begin{array}{l}\text { Espaços e objetos adaptados (LOPES; CAPELLINI, 2015). } \\
\text { Infraestrutura física adequada e ambientes seguros e inclusivos (Marco de } \\
\text { Ação da Educação 2030). } \\
\text { Educação especial pela ótica da inclusão educacional (MARCÓCCIA, 2011). }\end{array}$ \\
\hline
\end{tabular}

Fonte: Castro (2018, no prelo), com adaptações. 
Considerando essas dimensões e as variáveis que as compõem, para a composição das escalas, foram analisados todos os 55 itens dos blocos sobre caracterização e infraestrutura e sobre equipamentos do questionário de escola do Censo de 2017. Destaca-se que, nesses blocos de questões, identificou-se um conjunto de variáveis que não são consideradas pela matriz de especificação do conceito e que também não foram consideradas no presente estudo por não serem características da infraestrutura escolar, tais como: destinação do lixo; alojamento de alunos e de professor; lavanderia; retroprojetor; videocassete e internet banda larga.

Outros conjuntos de variáveis que não são considerados na matriz de especificação do conceito, mas que foram incluídos pelo estudo na composição operacional das escalas, estão compreendidos nas seguintes dimensões: infraestrutura básica (forma de ocupação do prédio, local de funcionamento da escola, água consumida pelos alunos); infraestrutura predial (quantidade de salas utilizadas como salas de aula) e infraestrutura pedagógica (pátio coberto e descoberto). O Quadro 2 apresenta todas as variáveis que efetivamente foram consideradas para as análises de calibração dos itens, em cada etapa de ensino. 


\section{Quadro 2 - Itens do censo escolar de 2017 utilizados para a composição das escalas dos segmentos de ensino}

\begin{tabular}{|c|c|c|c|c|}
\hline Item & Descrição & ei & ef & em \\
\hline 1 & Forma de ocupação do prédio & Sim & Sim & Sim \\
\hline 2 & Local de funcionamento da escola & Sim & Sim & Sim \\
\hline 3 & Água consumida pelos alunos & Sim & Sim & Sim \\
\hline 4 & Abastecimento de água & Sim & Sim & $\operatorname{Sim}$ \\
\hline 5 & Abastecimento de energia & Sim & Sim & Sim \\
\hline 6 & Esgoto sanitário & Sim & $\operatorname{Sim}$ & $\operatorname{Sim}$ \\
\hline 7 & Sala de diretoria & Sim & Sim & Sim \\
\hline 8 & Sala de professor & $\operatorname{Sim}$ & $\operatorname{Sim}$ & $\operatorname{Sim}$ \\
\hline 9 & Sala de recursos multifuncionais para Atendimento Educacional Especializado (AEE) & $\operatorname{Sim}$ & $\operatorname{Sim}$ & $\operatorname{Sim}$ \\
\hline 10 & Laboratório de informática & Não & Sim & $\operatorname{Sim}$ \\
\hline 11 & Laboratório de ciências & Não & Sim & $\operatorname{Sim}$ \\
\hline 12 & Cozinha & $\operatorname{Sim}$ & Não & Não \\
\hline 13 & Biblioteca & $\operatorname{Sim}$ & Sim & Sim \\
\hline 14 & Sala de leitura & $\operatorname{Sim}$ & Sim & $\operatorname{Sim}$ \\
\hline 15 & Banheiro & Não & Sim & Sim \\
\hline 16 & Banheiro de El & $\operatorname{Sim}$ & Não & Não \\
\hline 17 & $\begin{array}{l}\text { Banheiro acessível, adequado ao uso dos alunos com deficiência ou mobilidade } \\
\text { reduzida }\end{array}$ & $\operatorname{Sim}$ & Sim & $\operatorname{Sim}$ \\
\hline 18 & Dependências e vias adequadas a alunos com deficiência ou mobilidade reduzida & $\operatorname{Sim}$ & $\operatorname{Sim}$ & $\operatorname{Sim}$ \\
\hline 19 & Secretaria & $\operatorname{Sim}$ & Sim & Sim \\
\hline 20 & Banheiro com chuveiro & $\operatorname{Sim}$ & Não & Não \\
\hline 21 & Refeitório & $\operatorname{Sim}$ & Sim & Sim \\
\hline 22 & Despensa & $\operatorname{Sim}$ & Não & Não \\
\hline 23 & Almoxarifado & Sim & Sim & Sim \\
\hline 24 & Auditório & Não & Sim & $\operatorname{Sim}$ \\
\hline 25 & Área verde & $\operatorname{Sim}$ & $\operatorname{Sim}$ & $\operatorname{Sim}$ \\
\hline 26 & Número de salas utilizadas como sala de aula (dentro e fora do prédio) & Sim & Sim & Sim \\
\hline 27 & Aparelho de televisão & $\operatorname{Sim}$ & $\operatorname{Sim}$ & $\operatorname{Sim}$ \\
\hline 28 & Aparelho de DVD & $\operatorname{Sim}$ & Sim & $\operatorname{Sim}$ \\
\hline 29 & Copiadora & Sim & Sim & $\operatorname{Sim}$ \\
\hline 30 & Impressora & $\operatorname{Sim}$ & Sim & $\operatorname{Sim}$ \\
\hline 31 & Impressora multifuncional & Sim & Sim & Sim \\
\hline 32 & Aparelho de som & Sim & Sim & $\operatorname{Sim}$ \\
\hline 33 & Projetor multimídia (datashow) & $\operatorname{Sim}$ & Sim & $\operatorname{Sim}$ \\
\hline 34 & Máquina fotográfica/Filmadora & Sim & Sim & Sim \\
\hline 35 & Computador & Sim & Sim & $\operatorname{Sim}$ \\
\hline 36 & Computadores para uso administrativo & $\operatorname{Sim}$ & Sim & $\operatorname{Sim}$ \\
\hline 37 & Computadores para uso dos alunos & Sim & Sim & Sim \\
\hline 38 & Acesso à internet & Sim & Sim & Sim \\
\hline 39 & Pátio coberto e descoberto & Sim & Sim & Sim \\
\hline 40 & Quadra de esporte coberta e descoberta & Não & Sim & Sim \\
\hline 41 & Parque infantil & Sim & Não & Não \\
\hline 42 & Berçário & Sim & Não & Não \\
\hline
\end{tabular}

Fonte: Elaboração da autora.

Essa análise inicial verificou a relevância de todas as variáveis para cada uma das etapas de ensino, bem como o tipo de tratamento necessário para aquelas que são politômicas, ou seja, que são de múltipla escolha ou que indicam a quantidade dos recursos avaliados. Para todas as essas variáveis de múltipla 
escolha ou quantitativas, foram criadas categorias ou intervalos de valores como opções de respostas, a fim de considerar a qualidade ou a quantidade avaliada pelo item e não apenas o atributo da existência, como é estimado pelos itens dicotômicos.

Nas análises de respostas graduais pela TRI, os itens com maior desejabilidade foram classificados como nível 1, que representa o recurso ou o nível de qualidade desejável para todas as escolas. Por exemplo, é desejável que todas as escolas da educação básica, ao responderem ao questionário do Censo, tenham indicado que possuem abastecimento de água por meio da rede pública. Para as variáveis quantitativas, as categorias foram estabelecidas com base na análise de frequência das respostas, considerando que elas fossem quantitativamente comparáveis em cada uma das categorias e para cada um dos segmentos de ensino analisado.

Estimação dos parâmetros dos itens para cada segmento de ensino

Para a realização desta etapa do estudo, foi acessada a base de dados do Censo Escolar de 2017 com 285.540 escolas, incluindo públicas e privadas, rurais e urbanas e de todos os segmentos de ensino. O primeiro filtro feito nessa base foi na variável Situação de Funcionamento, considerando apenas as escolas "Em Atividade". Após essa filtragem, a base ficou reduzida a 181.611 escolas.

Em seguida, foi aplicado um filtro na variável "Etapa de Ensino", com a finalidade de considerar apenas as escolas que autodeclararam ofertar exclusivamente cada um dos segmentos de ensino. Esse procedimento foi adotado a fim de se garantir que as respostas em cada uma das alternativas das variáveis fossem coerentes com as diferentes realidades das escolas exclusivas daquela etapa de ensino e, consequentemente, permitissem uma melhor calibração dos parâmetros. Assim, chegou-se a três bancos específicos para cada etapa: El, com 83.052 escolas; EF, com 100.899; e EM, com 24.825.

Feito esse tratamento, passou-se à segunda etapa da pesquisa, que é a análise inicial utilizando o software livre R, com o auxílio dos pacotes psych e mirt, versão 3.3.0 para estimação dos parâmetros dos itens, também conhecida como calibração. O processo de calibração dos itens foi realizado via TRI, para itens construídos em escala gradual, que consistiu em estimar conjuntamente os parâmetros de um item. Essas estimativas foram produzidas com base na distribuição de frequências dos padrões de respostas dos respondentes (SAMEJIMA, 1969). Para tanto, foi utilizado o MRG, que trabalha com itens que apresentam mais de duas opções de respostas em um formato gradativo e 
que normalmente exigem do respondente uma avaliação sobre o assunto, para a escolha das alternativas.

O modelo MRG permite calcular a probabilidade de uma escola com determinado nível de infraestrutura responder a uma alternativa a partir dos parâmetros de discriminação dos itens e de dificuldade das alternativas. Ou seja, este modelo assume que os escores das categorias de um item $i$ são arranjados em ordem do menor para o maior e denotados por $k=0,1, \cdots, m_{i}$ onde $\left(m_{i}+1\right)$ é o número de categorias do $i$ - ésimo item. A probabilidade de um respondente $\boldsymbol{j}$, com score $\theta_{j}$, escolher uma categoria ou outra mais alta do item $i$ é dada por:

$P_{i, k}^{+}\left(\theta_{j}\right)=\frac{1}{1+e^{-D a_{i}\left(\theta_{j}-b_{i, k}\right)}}$

$b_{i, k}$ : é o parâmetro de dificuldade da $k$ - ésima categoria do item $i$. Esse parâmetro refere-se à probabilidade de um respondente com determinado score selecionar uma categoria de resposta (por exemplo, discordo totalmente) ou uma categoria mais alta ordenada (2, 3 ou concordo totalmente).

$\theta_{j}$ : score do $j$ - ésimo respondente.

$a_{i}$ : é o parâmetro de discriminação do item $i$, com o valor proporcional à inclinação da Curva Característica do Item $(\mathrm{CCl})$ no ponto $b_{i}$. Este parâmetro representa o quanto um item discrimina entre os respondentes de diferentes scores.

$D$ : é um fator de escala constante e igual a 1. Utiliza-se o valor 1,7 quando se deseja que a função logística forneça resultado semelhante ao da função ogiva normal.

Assim, nesse modelo, o parâmetro de discriminação " $a$ " representa a capacidade de distinguir escolas com diferentes níveis de traço latente. Ou seja, diferencia as escolas que avaliaram os itens dos questionários como não existentes daquelas que apontam possuir os recursos, indicando, ainda, em que intensidade eles existem em suas dependências. Teoricamente, essa discriminação pode variar de $-\infty$ a $+\infty$. Porém, na prática, o valor da discriminação varia de 0 (zero), considerada uma discriminação muito baixa, a 4 (quatro), considerada uma discriminação muito alta.

O parâmetro de dificuldade "b", no MRG, está associado à probabilidade das escolas com determinado nível de infraestrutura selecionar uma ou outra categoria/alternativa de resposta (por exemplo, “inexistente" ou "rede pública”). 
É com base nos parâmetros de dificuldade dos itens, representados em uma escala que varia, em geral, de -4 a 4 , que as categorias de resposta aos itens são estabelecidas. Para cada item do questionário, o número de parâmetros de dificuldade estimados é igual ao número de alternativas de resposta.

Por exemplo, no item 4 "Abastecimento de água”, os respondentes do questionário deveriam indicar, entre as cinco opções de respostas, qual melhor representava a proveniência do abastecimento de água para a escola. Considerando o nível de desejabilidade da resposta, no caso do item 4, as escolas que confirmam a proveniência do abastecimento de água via rede pública foram classificadas no nível 1. Quando elas não possuem abastecimento via rede pública, espera-se que tenham acesso a outros tipos de abastecimento (poço artesiano, cacimba/cisterna/poço ou de fonte/rio/igarapé/riacho/córrego), resposta classificada no nível 2 ou 3. Por fim, aquelas escolas que não têm abastecimento de água foram classificadas no nível 4. Assim, a probabilidade de uma escola optar pela alternativa "rede pública", representada pelo nível 1, aumenta à medida que o seu traço latente ou nível de infraestrutura também aumenta.

As Tabelas 1 a 3 apresentam os resultados dessa análise, com os itens que irão compor as escalas de infraestrutura escolar específicas para cada um dos segmentos de ensino e seus parâmetros de discriminação e de dificuldade na escala $(0,1)$, ou seja, em uma escala com média 0 e desvio padrão 1. Para a interpretação das tabelas, deve-se considerar os critérios definidos por Baker (2001), em que os parâmetros de discriminação " $a$ " variam de 0,35 (considerados baixos) a 1,70 (considerados muito altos). Em relação aos parâmetros de dificuldade "b", onde constar "-", lê-se itens que não possuem categorias ou alternativas de respostas naquele nível. 
Tabela 1 - Estimativas do parâmetro de discriminação " $a$ " e de dificuldade " $b$ " dos itens da escala de infraestrutura escolar da educação infantil

\begin{tabular}{|c|c|c|c|c|c|c|c|}
\hline Item & Descrição & $\begin{array}{l}\text { Parâmetro } \\
\text { "a" }\end{array}$ & $\begin{array}{l}\text { Parâmetro } \\
\text { "b" } 1\end{array}$ & $\begin{array}{l}\text { Parâmetro } \\
\text { "b" } 2\end{array}$ & $\begin{array}{l}\text { Parâmetro } \\
\text { "b" } 3\end{array}$ & $\begin{array}{l}\text { Parâmetro } \\
\text { "b" } 4\end{array}$ & $\begin{array}{l}\text { Parâmetro } \\
\text { "b" } 5\end{array}$ \\
\hline 1 & Forma de ocupação do prédio & 0,37 & $-3,66$ & $-2,78$ & - & - & - \\
\hline 2 & Local de funcionamento da escola & 1,21 & $-5,15$ & - & - & - & - \\
\hline 3 & Abastecimento de água & 1,30 & $-4,92$ & $-2,54$ & - & - & - \\
\hline 4 & Abastecimento de energia & 1,52 & $-5,22$ & $-4,38$ & - & - & - \\
\hline 5 & Esgoto sanitário & 0,89 & $-6,55$ & $-1,21$ & - & - & - \\
\hline 6 & Sala de diretoria & 0,96 & $-1,23$ & - & - & - & - \\
\hline 7 & Sala de professor & 1,32 & 0,08 & - & - & - & - \\
\hline 8 & $\begin{array}{l}\text { Sala de recursos multifuncionais } \\
\text { para Atendimento Educacional } \\
\text { Especializado (AEE) }\end{array}$ & 0,97 & 3,46 & - & - & - & - \\
\hline 9 & Cozinha & 0,81 & $-4,58$ & - & - & - & - \\
\hline 10 & Biblioteca & 0,91 & 1,93 & - & - & - & - \\
\hline 11 & Sala de leitura & 0,70 & 2,19 & - & - & - & - \\
\hline 12 & $\begin{array}{l}\text { Banheiro acessível, adequado ao } \\
\text { uso dos alunos com deficiência ou } \\
\text { mobilidade reduzida }\end{array}$ & 1,18 & 0,84 & - & - & - & - \\
\hline 13 & $\begin{array}{l}\text { Dependências e vias adequadas a } \\
\text { alunos com deficiência ou mobilidade } \\
\text { reduzida }\end{array}$ & 1,31 & 1,20 & - & - & - & - \\
\hline 14 & Secretaria & 1,05 & $-0,49$ & - & - & - & - \\
\hline 15 & Banheiro com chuveiro & 0,87 & $-0,85$ & - & - & - & - \\
\hline 16 & Refeitório & 1,29 & $-0,92$ & - & - & - & - \\
\hline 17 & Despensa & 0,78 & $-1,15$ & - & - & - & - \\
\hline 18 & Almoxarifado & 1,19 & 0,16 & - & - & - & - \\
\hline 19 & Área verde & 0,80 & 0,96 & - & - & - & - \\
\hline 20 & $\begin{array}{l}\text { Número de salas utilizadas como sala } \\
\text { de aula (dentro e fora do prédio) }\end{array}$ & 1,08 & 1,24 & 2,71 & 4,11 & 5,12 & - \\
\hline 21 & Aparelho de televisão & 1,17 & $-2,51$ & $-0,20$ & 0,78 & 1,86 & - \\
\hline 22 & Aparelho de DVD & 1,03 & $-2,09$ & 0,25 & 1,23 & - & - \\
\hline 23 & Copiadora & 0,86 & 0,69 & 3,38 & - & - & - \\
\hline 24 & Impressora & 0,99 & $-0,68$ & 1,48 & 2,91 & 4,12 & 6,63 \\
\hline 25 & Impressora multifuncional & 0,72 & 0,08 & 5,23 & - & - & - \\
\hline 26 & Aparelho de som & 1,37 & $-1,38$ & 0,11 & 1,06 & - & - \\
\hline 27 & Projetor multimídia (datashow) & 1,50 & 0,50 & 2,39 & 3,21 & 4,29 & - \\
\hline 28 & Máquina fotográfica/Filmadora & 1,28 & $-0,01$ & 1,93 & 3,60 & - & - \\
\hline 29 & Computador & 2,20 & 1,52 & 2,29 & 2,93 & 3,50 & - \\
\hline 30 & Computadores para uso administrativo & 2,24 & 1,13 & 2,36 & 3,14 & - & - \\
\hline 31 & Computadores para uso dos alunos & 1,65 & 1,74 & 2,77 & 3,90 & - & - \\
\hline 32 & Acesso à internet & 1,73 & $-0,66$ & - & - & - & - \\
\hline 33 & Parque infantil & 1,50 & $-0,64$ & - & - & - & - \\
\hline 34 & Berçário & 0,75 & 0,01 & - & - & - & - \\
\hline 35 & Banheiro de El & 1,14 & $-0,92$ & - & - & - & - \\
\hline
\end{tabular}


Tabela 2 - Estimativas do parâmetro de discriminação " $a$ " e de dificuldade " $b$ " dos itens da escala de infraestrutura escolar do ensino fundamental

\begin{tabular}{|c|c|c|c|c|c|c|c|}
\hline Item & Descrição & $\begin{array}{l}\text { Parâmetro } \\
\text { "a" }\end{array}$ & $\begin{array}{l}\text { Parâmetro } \\
\text { "b" } 1\end{array}$ & $\begin{array}{l}\text { Parâmetro } \\
\text { "b" } 2\end{array}$ & $\begin{array}{l}\text { Parâmetro } \\
\text { "b" } 3\end{array}$ & $\begin{array}{l}\text { Parâmetro } \\
\text { "b" } 4\end{array}$ & $\begin{array}{l}\text { Parâmetro } \\
\text { "b" } 5\end{array}$ \\
\hline 1 & Forma de ocupação do prédio & 0,76 & $-3,76$ & $-2,18$ & - & - & - \\
\hline 2 & Água consumida pelos alunos & 0,41 & $-14,53$ & $-4,65$ & - & - & - \\
\hline 3 & Abastecimento de água & 1,34 & $-6,16$ & $-4,80$ & - & - & - \\
\hline 4 & Abastecimento de energia & 0,40 & $-11,42$ & $-0,86$ & - & - & - \\
\hline 5 & Esgoto sanitário & 1,17 & $-2,33$ & - & - & - & - \\
\hline 6 & Sala de diretoria & 1,66 & $-1,95$ & - & - & - & - \\
\hline 7 & Sala de professor & 2,21 & $-0,92$ & - & - & - & - \\
\hline 8 & Laboratório de informática & 1,23 & 0,08 & - & - & - & - \\
\hline 9 & Laboratório de ciências & 0,57 & 3,10 & - & - & - & - \\
\hline 10 & $\begin{array}{l}\text { Sala de recurso multifuncionais } \\
\text { para Atendimento Educacional } \\
\text { Especializado (AEE) }\end{array}$ & 1,31 & $-0,91$ & - & - & - & - \\
\hline 11 & Biblioteca & 0,40 & 2,27 & - & - & - & - \\
\hline 12 & Sala de leitura & 1,14 & $-0,51$ & - & - & - & - \\
\hline 13 & Banheiro & 0,82 & 0,23 & - & - & - & - \\
\hline 14 & $\begin{array}{l}\text { Banheiro acessível, adequado ao } \\
\text { uso dos alunos com deficiência ou } \\
\text { mobilidade reduzida }\end{array}$ & 1,43 & $-1,70$ & - & - & - & - \\
\hline 15 & $\begin{array}{l}\text { Dependências e vias adequadas a } \\
\text { alunos com deficiência ou mobilidade } \\
\text { reduzida }\end{array}$ & 0,57 & 0,67 & - & - & - & - \\
\hline 16 & Secretaria & 0,94 & $-0,41$ & - & - & - & - \\
\hline 17 & Refeitório & 1,13 & 0,72 & - & - & - & - \\
\hline 18 & Almoxarifado & 0,70 & 0,95 & - & - & - & - \\
\hline 19 & Auditório & 0,89 & $-0,62$ & 0,41 & 1,61 & 2,65 & - \\
\hline 20 & Área verde & 1,00 & $-2,08$ & $-0,63$ & 0,34 & 1,34 & - \\
\hline 21 & $\begin{array}{l}\text { Número de salas utilizadas como sala } \\
\text { de aula (dentro e fora do prédio) }\end{array}$ & 0,69 & $-1,29$ & 0,79 & 2,41 & - & - \\
\hline 22 & Aparelho de televisão & 0,53 & $-0,45$ & 2,00 & - & - & - \\
\hline 23 & Aparelho de DVD & 0,96 & $-1,46$ & $-0,37$ & 0,39 & 1,08 & 2,02 \\
\hline 24 & Copiadora & 0,78 & $-0,36$ & 1,70 & - & - & - \\
\hline 25 & Impressora & 0,80 & $-1,28$ & 0,54 & 2,57 & - & - \\
\hline 26 & Impressora multifuncional & 1,26 & $-1,41$ & $-0,44$ & 0,22 & 0,95 & - \\
\hline 27 & Aparelho de som & 1,10 & $-0,51$ & 1,08 & 2,72 & - & - \\
\hline 28 & Projetor multimídia (datashow) & 8,80 & $-0,71$ & $-0,19$ & 0,16 & 0,55 & - \\
\hline 29 & Máquina fotográfica/Filmadora & 2,83 & $-0,57$ & 0,23 & 0,71 & - & - \\
\hline 30 & Computador & 6,01 & $-0,74$ & $-0,09$ & 0,29 & - & - \\
\hline 31 & $\begin{array}{l}\text { Computadores para uso } \\
\text { administrativo }\end{array}$ & 1,96 & $-1,69$ & - & - & - & - \\
\hline 32 & Computadores para uso dos alunos & 0,76 & $-3,76$ & $-2,18$ & - & - & - \\
\hline 33 & Acesso à internet & 0,41 & $-14,53$ & $-4,65$ & - & - & - \\
\hline
\end{tabular}

Fonte: Elaboração da autora. 
Tabela 3 - Estimativas do parâmetro de discriminação " $a$ " e de dificuldade " $b$ " dos itens da escala de infraestrutura escolar do ensino médio

\begin{tabular}{|c|c|c|c|c|c|c|c|}
\hline Item & Descrição & $\begin{array}{l}\text { Parâmetro } \\
\text { "a" }\end{array}$ & $\begin{array}{l}\text { Parâmetro } \\
\text { "b" } 1\end{array}$ & $\begin{array}{l}\text { Parâmetro } \\
\text { "b" } 2\end{array}$ & $\begin{array}{c}\text { Parâmetro } \\
\text { " } b " 3\end{array}$ & $\begin{array}{c}\text { Parâmetro } \\
\text { "b" } 4\end{array}$ & $\begin{array}{l}\text { Parâmetro } \\
\text { "b" } 5\end{array}$ \\
\hline 1 & Forma de ocupação do prédio & 0,76 & $-3,76$ & $-2,18$ & - & - & - \\
\hline 2 & Abastecimento de água & 0,41 & $-14,53$ & $-4,65$ & - & - & - \\
\hline 3 & Abastecimento de energia & 1,34 & $-6,16$ & $-4,80$ & - & - & - \\
\hline 4 & Esgoto sanitário & 0,40 & $-11,42$ & $-0,86$ & - & - & - \\
\hline 5 & Sala de diretoria & 1,17 & $-2,33$ & - & - & - & - \\
\hline 6 & Sala de professor & 1,66 & $-1,95$ & - & - & - & - \\
\hline 7 & Laboratório de informática & 2,21 & $-0,92$ & - & - & - & - \\
\hline 8 & Laboratório de ciências & 1,23 & 0,08 & - & - & - & - \\
\hline 9 & $\begin{array}{l}\text { Sala de recurso multifuncionais } \\
\text { para Atendimento Educacional } \\
\text { Especializado (AEE) }\end{array}$ & 0,57 & 3,10 & - & - & - & - \\
\hline 10 & Biblioteca & 1,31 & $-0,91$ & - & - & - & - \\
\hline 11 & Sala de leitura & 0,40 & 2,27 & - & - & - & - \\
\hline 12 & $\begin{array}{l}\text { Banheiro acessível, adequado ao } \\
\text { uso dos alunos com deficiência ou } \\
\text { mobilidade reduzida }\end{array}$ & 1,14 & $-0,51$ & - & - & - & - \\
\hline 13 & $\begin{array}{l}\text { Dependências e vias adequadas a } \\
\text { alunos com deficiência ou mobilidade } \\
\text { reduzida }\end{array}$ & 0,82 & 0,23 & - & - & - & - \\
\hline 14 & Secretaria & 1,43 & $-1,70$ & - & - & - & - \\
\hline 15 & Refeitório & 0,57 & 0,67 & - & - & - & - \\
\hline 16 & Almoxarifado & 0,94 & $-0,41$ & - & - & - & - \\
\hline 17 & Auditório & 1,13 & 0,72 & - & - & - & - \\
\hline 18 & Área verde & 0,70 & 0,95 & - & - & - & - \\
\hline 19 & $\begin{array}{l}\text { Número de salas utilizadas como sala } \\
\text { de aula (dentro e fora do prédio) }\end{array}$ & 0,89 & $-0,62$ & 0,41 & 1,61 & 2,65 & - \\
\hline 20 & Aparelho de televisão & 1,00 & $-2,08$ & $-0,63$ & 0,34 & 1,34 & - \\
\hline 21 & Aparelho de DVD & 0,69 & $-1,29$ & 0,79 & 2,41 & - & - \\
\hline 22 & Copiadora & 0,53 & $-0,45$ & 2,00 & - & - & - \\
\hline 23 & Impressora & 0,96 & $-1,46$ & $-0,37$ & 0,39 & 1,08 & 2,02 \\
\hline 24 & Impressora multifuncional & 0,78 & $-0,36$ & 1,70 & - & - & - \\
\hline 25 & Aparelho de som & 0,80 & $-1,28$ & 0,54 & 2,57 & - & - \\
\hline 26 & Projetor multimídia (datashow) & 1,26 & $-1,41$ & $-0,44$ & 0,22 & 0,95 & - \\
\hline 27 & Máquina fotográfica/Filmadora & 1,10 & $-0,51$ & 1,08 & 2,72 & - & - \\
\hline 28 & Computador & 8,80 & $-0,71$ & $-0,19$ & 0,16 & 0,55 & - \\
\hline 29 & Computadores para uso administrativo & 2,83 & $-0,57$ & 0,23 & 0,71 & - & - \\
\hline 30 & Computadores para uso dos alunos & 6,01 & $-0,74$ & $-0,09$ & 0,29 & - & - \\
\hline 31 & Acesso à internet & 1,96 & $-1,69$ & - & - & - & - \\
\hline 32 & Banheiro & 0,46 & $-8,88$ & $-2,00$ & - & - & - \\
\hline
\end{tabular}

Fonte: Elaboração da autora. 
Definição e descrição das escalas de infraestrutura escolar para todos os segmentos de ensino

Adotando como base o estudo de Beaton e Allen (1992) ${ }^{4}$, foram definidos os itens-âncora de cada um dos níveis da escala de desempenho, ou seja, aqueles que são característicos de um ponto ou um nível da escala em virtude da grande maioria das escolas situadas naquele nível indicar que possuem o recurso. O posicionamento dado pela proporção empírica, tende a se assemelhar ao posicionamento previsto pela TRI, alcançando-se uma distribuição dos itens e das escolas semelhante ao de uma curva normal na escala de infraestrutura.

A fim de se estabelecer os pontos de corte da escala, o valor da média, do desvio padrão, dos parâmetros dos itens e dos scores das escolas, que foram calculados originalmente na métrica $(0 ; 1)$, foram transformados para uma escala cuja média é 50 e o desvio padrão, 10. É esperado que a maior concentração de escolas esteja no intervalo de 40 a 60 pontos da escala, ou seja, no intervalo entre um desvio padrão abaixo e um desvio padrão acima da média. De modo a se aproximar ao máximo dessa distribuição normal, os intervalos foram estabelecidos com variações de 1 em 1 desvio padrão, com menor variabilidade nos níveis intermediários e maior variação nos extremos das escalas. Assim, definiu-se que as escalas de todos os segmentos seriam descritas em quatro níveis, assim denominados: elementar (score na escala de infraestrutura maior ou igual a 0 e menor que 30); básica (score na escala de infraestrutura maior ou igual a 30 e menor que 50); adequada (score na escala de infraestrutura maior ou igual a 50 e menor que 70); e avançada (score na escala de infraestrutura maior ou igual a 70).

\footnotetext{
${ }^{4}$ Essa metodologia estabelece três critérios para que o item possa ser classificado como âncora: (1) se a maioria das escolas situadas naquele nível da escala (mais de 65\%) responde positivamente ao item; (2) menos da metade das escolas situadas no nível imediatamente inferior também o responde positivamente; (3) a diferença entre os percentuais de resposta no ponto âncora e no ponto imediatamente anterior é igual ou superior a $30 \%$.
} 


\section{RESULTADOS E DISCUSSÃO}

Analisando os resultados de calibração dos itens, observa-se que os itens comuns a todos os segmentos de ensino apresentam parâmetros " $b$ " de dificuldade muito distintos, a depender do segmento analisado, reforçando a necessidade de especificação das escalas de infraestrutura escolar. Destaca-se o resultado dos itens que representam a dimensão da infraestrutura escolar básica (abastecimento de água, energia elétrica e esgoto), que, contrariamente às expectativas iniciais da pesquisa - por serem concebidos como itens indispensáveis -, apresentaram parâmetros de dificuldade muito altos e discrepantes ao comparar as três escalas.

Ainda em relação a esses itens da dimensão de infraestrutura básica, é desejável que, no processo de construção de medidas resumidas e padronizadas para o monitoramento de políticas públicas, o seu provimento seja garantido via rede pública. No entanto, observa-se que diversas escolas brasileiras podem não se encaixar nesse cenário em que a prestação de serviços públicos é a alternativa mais viável. Isso ocorre porque, considerando os contextos de escolas localizadas em áreas de assentamento, comunidades remanescentes de quilombolas e indígenas e unidades de uso sustentável, o abastecimento desses serviços via fontes alternativas (energia via geradores, eólica, solar, abastecimento de água via nascentes e poços e tratamento de esgoto via fossa séptica) parece ser ecologicamente mais coerente.

Diferentemente desses recursos básicos, os itens que compõem as demais dimensões operacionais da infraestrutura escolar (predial, equipamentos de apoio pedagógico, pedagógica e adequada às necessidades especiais) apresentaram parâmetros de dificuldade medianos e bem próximos, embora distintos, ao se analisar as escalas de cada um dos segmentos de ensino. Esses resultados corresponderam às expectativas iniciais, tendo em vista que, em geral, esses itens são considerados medianos ou fáceis, dada a sua relevância para cada uma das etapas de ensino.

Assim, na construção da interpretação das escalas de infraestrutura escolar específicas para cada um dos segmentos de ensino da educação básica, observa-se um maior nível de detalhamento quando são abordadas as variáveis que avaliam a qualidade da infraestrutura básica e as variáveis que avaliam quantitativamente os equipamentos de apoio pedagógico. Além disso, destaca-se o fato de ter sido possível, na composição das escalas, adequar a relevância dos itens que compõem a dimensão da infraestrutura pedagógica e o posicionamento que eles assumem, conforme a dificuldade calculada pelo parâmetro "b" da TRI. 
Como consequência, nas escalas da El, do EF e do EM, os itens característicos de cada uma dessas etapas que representam a dimensão da infraestrutura pedagógica foram posicionados no nível de infraestrutura adequada, conforme sua necessidade para o desenvolvimento educacional esperado nas diferentes etapas de ensino. No nível de infraestrutura avançada, foram posicionados apenas os itens que caracterizam a escola em relação ao seu porte, à quantidade de materiais e ao bem-estar oferecido aos estudantes que a frequentam, além dos itens relacionados à adequação ao atendimento de estudantes com deficiência ou mobilidade reduzida. Desse modo, as escalas tornam-se mais justas, pois consideram as especificidades e os diversos contextos dos diferentes segmentos de ensino e que o posicionamento das escolas no nível avançado, representa um avanço no porte da escola e não necessariamente na qualidade da sua infraestrutura. Nos Quadros 3 a 5, são apresentadas as propostas de descrições das escalas de infraestrutura escolar para a El, o EF e o EM, assim como o percentual de escolas do Censo de 2017 em cada intervalo da escala.

No Quadro 3, a média de desempenho das escolas brasileiras que autodeclararam no Censo Escolar de 2017 ofertar exclusivamente a El foi de 44,37 pontos na escala, apresentando uma infraestrutura escolar básica. Evidencia-se que essa média representa 36,40\% das escolas desse segmento, que, provavelmente, não possuem nos níveis desejáveis os itens essenciais à dimensão da infraestrutura básica, pois ocupam prédios alugados, são atendidas via rede pública apenas por água e, em relação à infraestrutura predial, apresentam somente cozinha e até 7 salas utilizadas como salas de aula. Elas não possuem infraestrutura pedagógica para a El e, em relação à infraestrutura de apoio pedagógico, contam somente com 5 computadores, sendo apenas 1 deles para uso dos estudantes, além de 1 aparelho de TV, DVD e de som.

Também é possível verificar a existência de um percentual muito similar $(35,73 \%)$ de escolas que apresentam uma infraestrutura escolar adequada. Segundo a escala da El, provavelmente, essas escolas possuem os requisitos desejáveis ao se considerar uma infraestrutura básica, como abastecimento de água, energia elétrica e esgoto sanitário provenientes de rede pública. Em relação à infraestrutura predial, elas dispõem, em suas dependências, de até 7 salas utilizadas como salas de aula, sala de diretoria e de professor, cozinha, secretaria, refeitório, despensa e almoxarifado. No que se refere à infraestrutura pedagógica, elas possuem todos os itens desejáveis a uma escola de El: banheiro com chuveiro e adequados à El, parque infantil e berçários. Na dimensão da infraestrutura de apoio pedagógico, essas escolas contam com um quantitativo maior de equipamentos se comparado com as escolas posi- 
cionadas no nível básico. Elas têm 2 aparelhos de televisão e de DVD; de 2 a 3 aparelhos de som; de 1 a 2 impressoras, sendo pelo menos 1 multifuncional; 1 equipamento de multimídia e 1 máquina fotográfica/filmadora; até 5 computadores, sendo apenas 1 deles para uso dos estudantes; e acesso à internet.

Ainda é preocupante o fato de que 22,88\% das escolas de El apresentam uma infraestrutura escolar elementar, visto que não apresentam nenhum dos requisitos desejáveis para a dimensão da infraestrutura escolar básica, da infraestrutura predial e de equipamentos pedagógicos. No lado oposto da escala, da infraestrutura escolar avançada, encontram-se apenas 4,99\% das escolas de El que se diferenciam das escolas do nível adequado apenas pela maior quantidade de equipamentos pedagógicos e pela dimensão predial que possuem. Destaca-se que essas escolas também já são capazes de atender estudantes com necessidades especiais.

Quadro 3 - Descrição e percentuais de escolas por intervalo de proficiência do indicador de infraestrutura escolar para a educação infantil

\begin{tabular}{|c|c|c|c|}
\hline Níveis da escala & Intervalos da escala & $\begin{array}{l}\text { Percentuais } \\
\text { de escolas }\end{array}$ & Descrição dos intervalos da escala de infraestrutura da EI \\
\hline \multirow[t]{2}{*}{1 - Elementar } & $\begin{array}{l}\text { Maior que } 0 \text { e menor } \\
\text { que } 10\end{array}$ & $1,24 \%$ & $\begin{array}{l}\text { Neste intervalo, considerando a dimensão da infraestrutura básica, as } \\
\text { escolas são caracterizadas por, provavelmente, ocupar espaços cedidos, cujos } \\
\text { locais de funcionamento são adversos (salas de empresa, templo de igrejas, } \\
\text { galpão, prédios compartilhados e unidades prisionais ou de atendimento } \\
\text { socioeducativo, salas de aulas em outras escolas e casa de professor); o } \\
\text { abastecimento de água é inexistente ou realizado por fontes alternativas } \\
\text { (cacimba, cisterna, poço, rio, igarapé, riacho ou córrego); o abastecimento } \\
\text { de energia elétrica é inexistente ou advém de fontes alternativas; e o } \\
\text { esgotamento sanitário é inexistente ou realizado através de fossa séptica. } \\
\text { Em relação à infraestrutura predial, essas escolas, provavelmente, possuem } \\
\text { até } 7 \text { salas utilizadas como salas de aula. Na dimensão da infraestrutura } \\
\text { para equipamentos de apoio pedagógico, provavelmente, possuem até } 5 \\
\text { computadores, sendo apenas } 1 \text { deles para uso dos estudantes. }\end{array}$ \\
\hline & $\begin{array}{l}\text { Maior ou igual a } 10 \text { e } \\
\text { menor que } 30\end{array}$ & $21,64 \%$ & $\begin{array}{l}\text { Além das condições citadas acima, as escolas neste intervalo, considerando a } \\
\text { dimensão da infraestrutura básica, provavelmente, já funcionam em prédios } \\
\text { escolares, possuem abastecimento de água por meio de poços artesianos, } \\
\text { a energia elétrica é proveniente de geradores e o esgoto sanitário, via fossa } \\
\text { séptica. Em relação à infraestrutura predial, essas escolas, provavelmente, } \\
\text { contam com cozinha em suas dependências. }\end{array}$ \\
\hline \multirow[t]{2}{*}{2 - Básica } & $\begin{array}{l}\text { Maior ou igual a } 30 \text { e } \\
\text { menor que } 40\end{array}$ & $16,17 \%$ & $\begin{array}{l}\text { Além dos itens citados no nível anterior, as escolas neste nível, considerando a } \\
\text { dimensão da infraestrutura básica, provavelmente, ocupam espaços alugados } \\
\text { e possuem abastecimento de água proveniente da rede pública. Em relação } \\
\text { à infraestrutura para equipamentos de apoio pedagógico, provavelmente, } \\
\text { possuem aparelho de televisão, mas ainda não contam com itens característicos } \\
\text { da dimensão pedagógica e adequada às necessidades especiais. }\end{array}$ \\
\hline & $\begin{array}{l}\text { Maior ou igual a } 40 \text { e } \\
\text { menor que } 50\end{array}$ & $20,23 \%$ & $\begin{array}{l}\text { Além das condições citadas acima, as escolas neste intervalo, considerando } \\
\text { a dimensão da infraestrutura básica, provavelmente, já ocupam espaços } \\
\text { próprios e, em relação à infraestrutura para equipamentos de apoio } \\
\text { pedagógico, provavelmente, possuem aparelho de DVD e de som. }\end{array}$ \\
\hline
\end{tabular}




\begin{tabular}{|c|c|c|c|}
\hline Níveis da escala & Intervalos da escala & $\begin{array}{l}\text { Percentuais } \\
\text { de escolas }\end{array}$ & Descrição dos intervalos da escala de infraestrutura da EI \\
\hline \multirow{2}{*}{3 - Adequada } & $\begin{array}{l}\text { Maior ou igual a } 50 \text { e } \\
\text { menor que } 60\end{array}$ & $22,18 \%$ & $\begin{array}{l}\text { Além dos itens citados nos níveis anteriores, as escolas neste nível, } \\
\text { considerando a dimensão da infraestrutura básica, provavelmente, possuem } \\
\text { esgoto sanitário proveniente da rede pública. Considerando a infraestrutura } \\
\text { predial e pedagógica, possuem sala de diretoria, secretaria, banheiro com } \\
\text { chuveiro e adequado à El, refeitório, despensa e parque infantil. Em relação } \\
\text { à infraestrutura para equipamentos de apoio pedagógico, as escolas neste } \\
\text { nível têm uma impressora. }\end{array}$ \\
\hline & $\begin{array}{l}\text { Maior ou igual a } 60 \text { e } \\
\text { menor que } 70\end{array}$ & $13,55 \%$ & $\begin{array}{l}\text { Além das condições citadas acima, as escolas neste intervalo, considerando } \\
\text { a infraestrutura predial e pedagógica, provavelmente, têm sala de professor, } \\
\text { almoxarifado e berçário. Considerando a infraestrutura para equipamentos } \\
\text { de apoio pedagógico, possuem uma maior quantidade de aparelhos de } \\
\text { televisão e de DVD (2) e de som ( } 2 \text { a 3), além de contarem com impressoras } \\
\text { multifuncionais, equipamento multimídia, máquina fotográfica/filmadora e } \\
\text { acesso à internet. }\end{array}$ \\
\hline \multirow{3}{*}{4 - Avançada } & $\begin{array}{l}\text { Maior ou igual a } 70 \text { e } \\
\text { menor que } 80\end{array}$ & $4,03 \%$ & $\begin{array}{l}\text { Além dos itens citados nos níveis anteriores, as escolas neste nível, } \\
\text { provavelmente, atendem à dimensão de infraestrutura adequada às } \\
\text { necessidades especiais, com banheiros e dependências acessíveis ao } \\
\text { uso dos alunos com deficiência ou mobilidade reduzida. Em relação à } \\
\text { infraestrutura predial, possuem área verde e um número maior de salas } \\
\text { utilizadas como salas de aula (8 a 10). Na dimensão de infraestrutura para } \\
\text { equipamentos de apoio pedagógico, as escolas têm uma maior quantidade } \\
\text { de impressoras ( } 2 \text { ), aparelhos de televisão (3 a 4), DVD (3), som (mais de 4), } \\
\text { copiadora e computadores (6 a 15), sendo pelo menos } 3 \text { computadores de uso } \\
\text { administrativo e de } 2 \text { a } 11 \text { destinados para uso dos alunos. }\end{array}$ \\
\hline & $\begin{array}{l}\text { Maior ou igual a } 80 \text { e } \\
\text { menor que } 90\end{array}$ & $0,85 \%$ & $\begin{array}{l}\text { Além das condições citadas acima, as escolas neste intervalo, provavelmente, } \\
\text { possuem em sua infraestrutura pedagógica biblioteca e sala de leitura. } \\
\text { Na dimensão de infraestrutura para equipamentos de apoio pedagógico, } \\
\text { têm uma maior quantidade de aparelhos de televisão (5), equipamentos de } \\
\text { multimídia (2), máquinas fotográficas/filmadoras ( } 2 \text { a } 3 \text { ) e computadores (16 a } \\
\text { 23), sendo pelo menos } 6 \text { computadores para uso administrativo. }\end{array}$ \\
\hline & Maior ou igual a 90 & $0,10 \%$ & $\begin{array}{l}\text { Além das condições citadas acima, as escolas neste intervalo, provavelmente, } \\
\text { atendem à dimensão infraestrutura adequada às necessidades especiais, } \\
\text { com sala de atendimento especial. Em relação à infraestrutura predial, } \\
\text { possuem um número maior de salas utilizadas como salas de aula (mais de 11). } \\
\text { Na dimensão de infraestrutura para equipamentos de apoio pedagógico, } \\
\text { as escolas têm uma maior quantidade de copiadoras (2), impressoras (3), } \\
\text { equipamentos de multimídia (mais de } 3 \text { ), máquinas fotográficas/filmadoras (mais } \\
\text { de 4) e computadores (mais de } 24 \text { ), sendo pelo menos } 10 \text { computadores para } \\
\text { uso administrativo e } 12 \text { para uso dos alunos. }\end{array}$ \\
\hline
\end{tabular}

Fonte: Elaboração da autora.

No Quadro 4, é apresentada a escala de infraestrutura escolar do EF e é que apresenta a menor quantidade de variáveis operacionais ou características da dimensão pedagógica dessa etapa de ensino, pois todos os itens considerados na sua composição são comuns e essenciais para os outros segmentos, como biblioteca e laboratórios. A média na escala do indicador foi de 49,08 pontos, indicando que as escolas brasileiras que oferecem essa etapa de ensino possuem uma infraestrutura escolar básica, mas quase no nível adequado e desejado da escala. Nessa situação, estão 49,13\% das escolas brasileiras. 
Já as escolas posicionadas no nível adequado representam um percentual de 49,56\% e, provavelmente, contam com todos os recursos relacionados à dimensão da infraestrutura básica via rede pública, possuem em suas dependências uma estrutura predial de banheiros dentro e fora da escola, têm mais de 8 salas utilizadas como salas de aula, além de diretoria e de professor, secretaria, refeitório e almoxarifado. Elas ainda dispõem de itens específicos da dimensão de infraestrutura adequada ao atendimento especial, com salas e banheiro acessível aos estudantes com deficiência. Considerando a dimensão da infraestrutura pedagógica, essas escolas possuem laboratório de informática, biblioteca e sala de leitura e contam com uma quantidade maior de equipamentos de apoio pedagógico: pelo menos 2 aparelhos de TV, DVD, som, foto, multimídia, copiadora, impressora (sendo pelo menos 1 multifuncional), de 6 a 23 computadores, sendo pelo menos 6 de uso administrativo e 11 destinados aos estudantes, e acesso à internet.

Nas extremidades da escala de infraestrutura específica para o EF, posiciona-se um percentual pouco expressivo de escolas (4,39\%), resultado que pode ser considerado, em certa medida, positivo, pois indica que, pelo menos no nível elementar, há poucas escolas desse segmento de ensino. Vale lembrar que todos os recursos escolares essenciais dessa etapa estão posicionados no nível adequado da escala de infraestrutura escolar.

Por fim, em relação ao EM, as escolas que autodeclaram ofertar exclusivamente essa etapa de ensino apresentaram a maior média de 52,28 pontos na escala de infraestrutura escolar. Essas escolas estão no nível de infraestrutura adequada e compreendem 61,22\% das escolas brasileiras. Elas, provavelmente, contam com todos os recursos relacionados à dimensão da infraestrutura básica via rede pública. Possuem, em suas dependências, uma estrutura predial com banheiros dentro e fora da escola e acessíveis aos estudantes com deficiência, além de sala de diretoria e de professor, secretaria, refeitório, almoxarifado, área verde, auditório e mais de 11 salas utilizadas como salas de aula. Em relação à infraestrutura pedagógica, essas escolas, provavelmente, possuem laboratórios de informática e de ciências, assim como biblioteca, e, na dimensão da infraestrutura adequada às necessidades especiais, elas contam com sala de atendimento especial. Essas escolas, provavelmente, ainda possuem uma quantidade maior de equipamentos pedagógicos: pelo menos 2 aparelhos de TV, DVD, som, foto, multimídia, copiadora, impressora (sendo pelo menos 1 multifuncional) e de 6 a 23 computadores, sendo pelo menos 6 de uso administrativo e 11 destinados aos estudantes, além de acesso à internet. Para o ensino médio, os resultados ainda demonstram que 36,78\% das escolas ainda não possuem uma infraestrutura mínima para ofertar esse 
seguimento de ensino, pois estão nos níveis elementar e básico da escala. Indicando as condições desiguais em que estas escolas se encontram, especialmente no que se refere a uma infraestrutura pedagógica mínima desejável. Destaca-se ainda, que os itens biblioteca e sala de leitura, que compõem a dimensão de infraestrutura pedagógica para todos os segmentos de ensino, se comportaram de modo inesperado ao se posicionaram no nível avançado das escalas da El e do EM (apenas sala de leitura). Esse posicionamento pode estar relacionado a uma não compreensão das escolas, no processo de auto declaração ao questionário do Censo Escolar, de que a sala de leitura também pode não ser compreendida como um espaço similar ou substitutivo da biblioteca ou a uma não usabilidade, de fato, desses espaços. Outro item relacionado à dimensão da infraestrutura pedagógica, posicionado no nível avançado da escala é o laboratório de ciências para o EF, indicando que há poucas escolas que contam que esse ambiente em suas dependências.

Ademais, destaca-se que, embora as três escalas não sejam metodologicamente comparáveis, os segmentos de ensino só passam a contar com todos os itens da infraestrutura básica a partir do nível adequado. Os itens relacionados à dimensão da infraestrutura adequada às necessidades especiais também são características de escolas que apresentam nível adequado e avançado, indicando, portanto, que escolas que fazem este tipo de atendimento pedagógico possuem melhores condições de infraestrutura.

A partir da interpretação dessas escalas, espera-se que todas as escolas da educação básica sejam posicionadas no nível adequado, onde todas as variáveis de infraestrutura pedagógica estão posicionadas. Esse nível passa a ser considerado como o patamar mínimo para o funcionamento escolar, independentemente do segmento. Desconstrói-se, assim, a ideia de que uma infraestrutura escolar ideal é representada pelo nível avançado, uma vez que esse nível é composto apenas por variáveis que indicam um avanço no porte das escolas. 
Quadro 4 - descrição e percentuais de escolas por intervalo de proficiência do indicador de infraestrutura escolar para o ensino fundamental

\begin{tabular}{|c|c|c|c|}
\hline Níveis da escala & Intervalos da escala & $\begin{array}{l}\text { Percentuais } \\
\text { de escolas }\end{array}$ & Descrição dos intervalos da escala de infraestrutura do EF \\
\hline 1 - Elementar & $\begin{array}{l}\text { Maior que } 20 \text { e } \\
\text { menor que } 30\end{array}$ & $3,07 \%$ & $\begin{array}{l}\text { Neste nível, considerando a dimensão da infraestrutura básica, as escolas, } \\
\text { provavelmente, são caracterizadas por ocupar espaços próprios, onde } \\
\text { os alunos consomem água filtrada, o abastecimento de água é via poços } \\
\text { artesianos, o fornecimento de energia elétrica advém de geradores e o } \\
\text { esgotamento sanitário é através de fossa séptica. Em relação à infraestrutura } \\
\text { predial, elas, provavelmente, possuem banheiros dentro e fora da escola e } \\
\text { até } 7 \text { salas utilizadas como salas de aula. Considerando a infraestrutura para } \\
\text { equipamentos de apoio pedagógico, elas, provavelmente, contam com até } 5 \\
\text { computadores, sendo apenas } 1 \text { deles para uso dos estudantes. }\end{array}$ \\
\hline & $\begin{array}{l}\text { Maior ou igual a } 30 \text { e } \\
\text { menor que } 40\end{array}$ & $19,84 \%$ & $\begin{array}{l}\text { Além dos itens citados no nível anterior, as escolas neste nível, considerando } \\
\text { a dimensão da infraestrutura básica, provavelmente, possuem abastecimento } \\
\text { de energia elétrica via rede pública. }\end{array}$ \\
\hline 2 - Básica & $\begin{array}{l}\text { Maior ou igual a } 40 \text { e } \\
\text { menor que } 50\end{array}$ & $26,21 \%$ & $\begin{array}{l}\text { Além das condições citadas acima, considerando a dimensão da infraestrutura } \\
\text { básica, as escolas neste intervalo, provavelmente, possuem abastecimento } \\
\text { de água também via rede pública. Em relação à infraestrutura predial, } \\
\text { provavelmente, possuem sala de diretoria e de professor e secretaria. } \\
\text { Considerando a infraestrutura para equipamentos de apoio pedagógico, } \\
\text { essas escolas, provavelmente, têm aparelho de TV, DVD, som, multimídia e } \\
\text { impressora, além de acesso à internet. }\end{array}$ \\
\hline \multirow[t]{2}{*}{3 - Adequada } & $\begin{array}{l}\text { Maior ou igual a } 50 \text { e } \\
\text { menor que } 60\end{array}$ & $35,72 \%$ & $\begin{array}{l}\text { Além dos itens citados nos níveis anteriores, considerando a dimensão da } \\
\text { infraestrutura básica, as escolas neste nível, provavelmente, possuem } \\
\text { esgotamento sanitário via rede pública e, em relação à infraestrutura predial, } \\
\text { possuem uma quantidade maior de salas utilizadas como salas de aula ( } 8 \\
\text { a 10), além de refeitório e almoxarifado. No que se refere à infraestrutura } \\
\text { pedagógica, provavelmente, contam com laboratórios de informática } \\
\text { e biblioteca. Considerando as dimensões pedagógica e adequada às } \\
\text { necessidades especiais, as escolas neste nível, provavelmente, contam } \\
\text { com salas de atendimento especial e banheiro acessível aos estudantes } \\
\text { com deficiência. Em relação à infraestrutura para equipamentos de apoio } \\
\text { pedagógico, provavelmente, possuem copiadora e uma maior quantidade de } \\
\text { aparelhos de TV (2) e DVD (2), equipamentos de som ( } 2 \text { a 3), impressoras (2) - } \\
\text { sendo pelo menos } 1 \text { multifuncional -, equipamentos de foto e computadores (6 } \\
\text { a 15), sendo pelo menos } 3 \text { para uso administrativo e de } 2 \text { a } 11 \text { para os alunos. }\end{array}$ \\
\hline & $\begin{array}{l}\text { Maior ou igual a } 60 \text { e } \\
\text { menor que } 70\end{array}$ & $13,84 \%$ & $\begin{array}{l}\text { Além das condições citadas acima, as escolas neste intervalo, considerando } \\
\text { a infraestrutura predial, provavelmente, possuem uma quantidade maior } \\
\text { de salas utilizadas como salas de aula (11 a 14). Em relação à infraestrutura } \\
\text { pedagógica, provavelmente, possuem sala de leitura e, em relação à } \\
\text { dimensão adequada às necessidades especiais, contam com dependências } \\
\text { adequadas para alunos com deficiência. No que se refere à infraestrutura } \\
\text { para equipamentos de apoio pedagógico, essas escolas, provavelmente, } \\
\text { possuem uma maior quantidade de copiadoras (2), equipamentos de foto ( } 2 \text { a } \\
\text { 3), impressoras (mais de } 3 \text { ) e aparelhos de TV (3 a 4), multimídia (4) e som (mais } \\
\text { de 4), além de computadores (16 a } 23 \text { ), sendo pelo menos } 6 \text { destinados ao uso } \\
\text { administrativo e } 12 \text { ao uso dos estudantes. }\end{array}$ \\
\hline
\end{tabular}




\begin{tabular}{|c|c|c|c|}
\hline Níveis da escala & Intervalos da escala & $\begin{array}{l}\text { Percentuais } \\
\text { de escolas }\end{array}$ & Descrição dos intervalos da escala de infraestrutura do EF \\
\hline \multirow[t]{2}{*}{4 - Avançada } & $\begin{array}{l}\text { Maior ou igual a } 70 \text { e } \\
\text { menor que } 80\end{array}$ & $1,28 \%$ & $\begin{array}{l}\text { Além dos itens citados nos níveis anteriores, considerando a infraestrutura } \\
\text { predial, as escolas neste nível, provavelmente, contam com auditório e área } \\
\text { verde em suas dependências. Em relação à infraestrutura pedagógica, } \\
\text { possuem laboratório de ciências. No que se refere à infraestrutura para } \\
\text { equipamentos de apoio pedagógico, essas escolas possuem uma maior } \\
\text { quantidade de impressoras multifuncionais (2), equipamentos de multimídia } \\
\text { (mais 5) e computadores (mais de } 24 \text { ). }\end{array}$ \\
\hline & Maior ou igual a 80 & $0,03 \%$ & $\begin{array}{l}\text { Além das condições citadas acima, considerando a infraestrutura predial, as } \\
\text { escolas neste intervalo, provavelmente, possuem uma quantidade maior de } \\
\text { salas utilizadas como salas de aula (mais de 15) e, em relação à infraestrutura } \\
\text { de apoio pedagógico, elas possuem mais de } 3 \text { impressoras multifuncionais. }\end{array}$ \\
\hline
\end{tabular}

Fonte: Elaboração da autora.

Quadro 5 - descrição e percentuais de escolas por intervalo de proficiência do indicador de infraestrutura escolar para o ensino médio

\begin{tabular}{|c|c|c|c|}
\hline Nível & Intervalo & $\begin{array}{l}\text { Percentual } \\
\text { de escolas }\end{array}$ & Descrição dos intervalos da escala de infraestrutura do EM \\
\hline \multirow[t]{2}{*}{1 - Elementar } & $\begin{array}{l}\text { Maior que } 10 \text { e menor } \\
\text { que } 20\end{array}$ & $0,24 \%$ & $\begin{array}{l}\text { Neste nível, considerando a dimensão da infraestrutura básica, as escolas } \\
\text { são caracterizadas, provavelmente, por ocupar espaços cedidos, onde o } \\
\text { abastecimento de água é realizado por fontes alternativas (cacimba, cisterna, } \\
\text { poço, rio, igarapé, riacho ou córrego) ou poço artesiano, o fornecimento de } \\
\text { energia elétrica advém de geradores ou fontes alternativas e o esgotamento } \\
\text { sanitário é por meio de fossa séptica. Em relação à infraestrutura predial, } \\
\text { provavelmente, possuem banheiros dentro do prédio e até } 7 \text { salas utilizadas } \\
\text { como salas de aula. No que se refere à infraestrutura de apoio pedagógico, } \\
\text { essas escolas, provavelmente, possuem até } 5 \text { computadores, sendo apenas } 1 \\
\text { deles para uso dos estudantes. }\end{array}$ \\
\hline & $\begin{array}{l}\text { Maior ou igual a } 20 \text { e } \\
\text { menor que } 30\end{array}$ & $1,81 \%$ & $\begin{array}{l}\text { Além das condições citadas acima, considerando a dimensão da } \\
\text { infraestrutura básica, as escolas neste intervalo, provavelmente, ocupam } \\
\text { espaços alugados e contam com abastecimento de água e energia elétrica } \\
\text { por meio da rede pública. Em relação à infraestrutura predial, provavelmente, } \\
\text { possuem banheiros dentro e fora do prédio. }\end{array}$ \\
\hline \multirow[b]{2}{*}{2 - Básica } & $\begin{array}{l}\text { Maior ou igual a } 30 \text { e } \\
\text { menor que } 40\end{array}$ & $5,18 \%$ & $\begin{array}{l}\text { Além dos itens citados no nível anterior, considerando a dimensão da } \\
\text { infraestrutura básica, as escolas neste nível, provavelmente, ocupam espaços } \\
\text { próprios e, considerando a dimensão da infraestrutura predial, elas possuem } \\
\text { sala de diretoria e de professores e secretaria. Em relação à infraestrutura de } \\
\text { apoio pedagógico, provavelmente, contam com aparelho de TV e multimídia, } \\
\text { impressora e acesso à internet. }\end{array}$ \\
\hline & $\begin{array}{l}\text { Maior ou igual a } 40 \text { e } \\
\text { menor que } 50\end{array}$ & $29,44 \%$ & $\begin{array}{l}\text { Além das condições citadas acima, considerando a infraestrutura predial, as } \\
\text { escolas neste intervalo, provavelmente, possuem uma quantidade maior de } \\
\text { salas utilizadas como salas de aulas ( } 8 \text { a 10). Essas escolas, provavelmente, } \\
\text { também passam a ter itens específicos da dimensão de infraestrutura } \\
\text { pedagógica, como laboratório de informática e biblioteca, bem como uma } \\
\text { infraestrutura adequada às necessidades especiais, com banheiros } \\
\text { adequados aos alunos com deficiência. Em relação à infraestrutura de } \\
\text { apoio pedagógico, provavelmente, contam com equipamento de DVD, som, } \\
\text { máquina fotográfica, aparelho de TV e multimídia e uma quantidade maior de } \\
\text { computadores (16 a } 23 \text { ), sendo pelo menos } 3 \text { de uso administrativo e de } 2 \text { a } 19 \\
\text { destinados aos alunos. }\end{array}$ \\
\hline
\end{tabular}




\begin{tabular}{|c|c|c|c|}
\hline Nível & Intervalo & $\begin{array}{l}\text { Percentual } \\
\text { de escolas }\end{array}$ & Descrição dos intervalos da escala de infraestrutura do EM \\
\hline \multirow[t]{2}{*}{3 - Adequada } & $\begin{array}{l}\text { Maior ou igual a } 50 \text { e } \\
\text { menor que } 60\end{array}$ & $46,22 \%$ & $\begin{array}{l}\text { Além dos itens citados nos níveis anteriores, considerando a dimensão da } \\
\text { infraestrutura básica, as escolas neste nível, provavelmente, possuem } \\
\text { esgotamento sanitário via rede pública e, em relação à infraestrutura predial, } \\
\text { elas possuem uma quantidade maior de salas utilizadas como salas de aula } \\
\text { (11 a 14), além de almoxarifado. No que se refere à infraestrutura pedagógica, } \\
\text { essas escolas, provavelmente, possuem laboratório de ciências e, na } \\
\text { dimensão da infraestrutura adequada às necessidades especiais, contam } \\
\text { com dependências adequadas a alunos com deficiência. Considerando a } \\
\text { infraestrutura de apoio pedagógico, elas, provavelmente, possuem copiadora } \\
\text { e uma quantidade maior de aparelhos de TV (2) e impressoras (2), sendo pelo } \\
\text { menos } 1 \text { multifuncional. }\end{array}$ \\
\hline & $\begin{array}{l}\text { Maior ou igual a } 60 \text { e } \\
\text { menor que } 70\end{array}$ & $15,01 \%$ & $\begin{array}{l}\text { Além das condições citadas acima, considerando a infraestrutura predial, } \\
\text { as escolas neste intervalo, provavelmente, possuem auditório e área verde. } \\
\text { Em relação à infraestrutura de apoio pedagógico, provavelmente, contam } \\
\text { com uma quantidade maior de aparelhos de TV (3 a 4) e de DVD (2), além de } \\
\text { impressoras (3). }\end{array}$ \\
\hline \multirow{2}{*}{4 - Avançada } & $\begin{array}{l}\text { Maior ou igual a } 70 \text { e } \\
\text { menor que } 80\end{array}$ & $2,03 \%$ & $\begin{array}{l}\text { Além dos itens citados nos níveis anteriores, considerando a infraestrutura } \\
\text { predial, as escolas neste nível, provavelmente, possuem uma quantidade } \\
\text { maior de salas utilizadas como sala de aula (15 a 18). Em relação à } \\
\text { infraestrutura de apoio pedagógico, provavelmente, contam com uma } \\
\text { quantidade maior de copiadoras (2), de aparelhos de DVD (mais de 3) e } \\
\text { impressoras (mais de 3), sendo pelo menos } 2 \text { multifuncionais. }\end{array}$ \\
\hline & Maior ou igual a 80 & $0,07 \%$ & $\begin{array}{l}\text { Além das condições citadas acima, considerando a dimensão da } \\
\text { infraestrutura adequada às necessidades especiais, as escolas neste } \\
\text { intervalo, provavelmente, possuem sala de atendimento especial e, } \\
\text { considerando a infraestrutura pedagógica, elas contam com sala de leitura. } \\
\text { Na dimensão da infraestrutura predial, provavelmente, têm uma quantidade } \\
\text { maior de salas utilizadas como salas de aula (mais de 19). }\end{array}$ \\
\hline
\end{tabular}

Fonte: Elaboração da autora.

Análises descritivas de cada uma das escalas dos segmentos de ensino, por região, dependência administrativa e localização das escolas

Após a descrição das escalas de infraestrutura, deu-se início às análises descritivas, estabelecendo-se, primeiramente, as médias e os percentuais de escolas em todas as escalas, por região, unidade da federação, dependência administrativa e localização. A Tabela 4 mostra, em termos absolutos e relativos, a distribuição das escolas nos intervalos e nos níveis das escalas. 
Tabela 4 - Quantitativo e percentuais de escolas nos intervalos de proficiência da escala de infraestrutura escolar, por segmento de ensino

\begin{tabular}{|c|c|c|c|c|c|c|c|}
\hline \multirow{2}{*}{$\begin{array}{c}\text { Níveis de } \\
\text { infraestrutura }\end{array}$} & \multirow{2}{*}{$\begin{array}{l}\text { Intervalos } \\
\text { da escala }\end{array}$} & \multicolumn{2}{|c|}{ EI } & \multicolumn{2}{|c|}{ EF } & \multicolumn{2}{|c|}{ EM } \\
\hline & & $\mathrm{N}$. & $\%$ & $\mathrm{~N}$. & $\%$ & $\mathrm{~N}$. & $\%$ \\
\hline \multirow{3}{*}{ Elementar } & $0<10$ & 1031 & 1,24 & 0 & 0,00 & 0 & 0,00 \\
\hline & $10<20$ & 6132 & 7,38 & 0 & 0,00 & 59 & 0,24 \\
\hline & $20<30$ & 11838 & 14,25 & 3098 & 3,07 & 450 & 1,81 \\
\hline \multirow{2}{*}{ Básica } & $30<40$ & 13433 & 16,17 & 20022 & 19,84 & 1287 & 5,18 \\
\hline & $40<50$ & 16802 & 20,23 & 26448 & 26,21 & 7309 & 29,44 \\
\hline \multirow{2}{*}{ Adequada } & $50<60$ & 18417 & 22,18 & 36037 & 35,72 & 11474 & 46,22 \\
\hline & $60<70$ & 11256 & 13,55 & 13966 & 13,84 & 3725 & 15,01 \\
\hline \multirow{3}{*}{ Avançada } & $70<80$ & 3351 & 4,03 & 1295 & 1,28 & 503 & 2,03 \\
\hline & $80<90$ & 709 & 0,85 & 33 & 0,03 & 18 & 0,07 \\
\hline & $90<100$ & 83 & 0,10 & 0 & 0,00 & 0 & 0,00 \\
\hline
\end{tabular}

Fonte: Elaboração da autora.

Nos intervalos que incluem as escolas com infraestrutura elementar em cada um dos segmentos de ensino, destaca-se a diferença entre os percentuais de escolas da El (22,88\%) e do EF e do EM (3,07\% e 2,05\%, respectivamente). Esse comportamento evidencia que o investimento na infraestrutura escolar da primeira infância deve ser prioridade na agenda das políticas públicas, dado o quantitativo de escolas que estão posicionadas três desvios abaixo do ponto considerado como o patamar mínimo da escala de infraestrutura escolar. O EF é o segmento com o maior percentual de escolas no nível básico $(46,06 \%)$ e o EM com o maior percentual de escolas no nível adequado (61,22\%). Todos os segmentos de ensino apresentaram um número pouco expressivo de escolas no nível avançado (4,99\%; 1,32\% e 2,10\%).

Na Tabela 5, são apresentadas as porcentagens de escolas de todos os segmentos de ensino, em cada um dos níveis da escala, por região geográfica do Brasil. Em qualquer uma das regiões, conforme esperado pela descrição das escalas, a porcentagem de escolas em todos os segmentos de ensino no nível avançado é sempre menor que 2\%. Observa-se que a região Sudeste apresenta o maior percentual de escolas no nível adequado para todos os segmentos.

No nível básico, a região Nordeste conta com o maior percentual de escolas da El (21,99\%) e do EF (29,11\%), enquanto a região Sudeste possui o maior percentual de escolas de EM no mesmo nível (14,18\%). Esse fato corrobora as vantagens em se analisar a infraestrutura escolar por escalas específicas, pois é possível observar que regiões como a Sudeste também apresentam um percentual expressivo de escolas que não possuem infraestrutura adequada para determinado segmento de ensino. Assim, são superados os prejulgamentos 
de que apenas as regiões Norte e Nordeste do país apresentam situações mais críticas de infraestrutura escolar, e endossa-se a tese de que o investimento em recursos escolares deve priorizar as regiões em que os segmentos de ensino apresentam níveis mais baixos de infraestrutura escolar. Por fim, no nível elementar das escalas, a região Norte apresenta o maior percentual de escolas do EF (2,34\%) e do EM (0,81\%), e a região Nordeste, da El (14,27\%).

Tabela 5 - Percentuais de escolas nos níveis da escala de infraestrutura escolar, por região e segmento de ensino

\begin{tabular}{|c|c|c|c|c|c|c|c|c|c|c|c|c|}
\hline \multirow{3}{*}{ Regiões } & \multicolumn{12}{|c|}{ Níveis de infraestrutura escolar } \\
\hline & \multicolumn{3}{|c|}{ Elementar } & \multicolumn{3}{|c|}{ Básica } & \multicolumn{3}{|c|}{ Adequada } & \multicolumn{3}{|c|}{ Avançada } \\
\hline & El & EF & EM & $\mathrm{El}$ & EF & EM & $\mathrm{El}$ & EF & EM & El & EF & EM \\
\hline Norte & $7,55 \%$ & $2,34 \%$ & $0,81 \%$ & $4,20 \%$ & $8,27 \%$ & $4,02 \%$ & $1,97 \%$ & $3,28 \%$ & $3,52 \%$ & $0,21 \%$ & $0,06 \%$ & $0,11 \%$ \\
\hline Nordeste & $14,27 \%$ & $0,70 \%$ & $0,36 \%$ & $21,99 \%$ & $29,11 \%$ & $9,71 \%$ & $9,99 \%$ & $12,47 \%$ & $9,03 \%$ & $0,83 \%$ & $0,20 \%$ & $0,36 \%$ \\
\hline Sudeste & $0,69 \%$ & $0,00 \%$ & $0,52 \%$ & $6,86 \%$ & $5,50 \%$ & $14,18 \%$ & $13,57 \%$ & $19,98 \%$ & $29,76 \%$ & $1,98 \%$ & $0,52 \%$ & $0,73 \%$ \\
\hline Sul & $0,16 \%$ & $0,01 \%$ & $0,26 \%$ & $2,20 \%$ & $1,99 \%$ & $3,48 \%$ & $6,99 \%$ & $9,37 \%$ & $13,60 \%$ & $1,48 \%$ & $0,42 \%$ & $0,71 \%$ \\
\hline Centro-Oeste & $0,20 \%$ & $0,03 \%$ & $0,10 \%$ & $1,15 \%$ & $1,19 \%$ & $3,25 \%$ & $3,21 \%$ & $4,47 \%$ & $5,31 \%$ & $0,49 \%$ & $0,11 \%$ & $0,19 \%$ \\
\hline Brasil & $22,88 \%$ & $3,07 \%$ & $2,05 \%$ & $36,40 \%$ & $0,00 \%$ & $34,63 \%$ & $35,73 \%$ & $49,56 \%$ & $61,22 \%$ & $4,99 \%$ & $1,32 \%$ & $2,10 \%$ \\
\hline
\end{tabular}

Fonte: Elaboração da autora.

A Tabela 6 apresenta em detalhes os resultados das escalas em relação à dependência administrativa, ou seja, se as escolas são federais, estaduais, municipais ou privadas, para cada um dos segmentos de ensino. Observa-se que as escolas privadas, embora que em percentuais pouco expressivos, são as que apresentam uma maior quantidade de escolas da El (3,15\%) e do EM (1,52\%) no nível avançado das escalas. Nos níveis de infraestrutura escolar adequada e básica, as escolas municipais se destacam tanto para a El (28,41\% e 19,61\%), quanto para o EF (37,99\% e 19,08\% e) e as escolas estaduais, para o $\operatorname{EM}(24,31 \%$ e $39,94 \%)$

Esses resultados refletem o atual regime de parceria entre União, estados, municípios e Distrito Federal na oferta de determinados segmentos de ensino, em que El e EF ficam sob a responsabilidade majoritariamente dos munícipios, enquanto o EM fica a cargo dos estados. Logo, considerar que escolas municipais apresentam melhor infraestrutura escolar para a El e para o EF e que as escolas estaduais oferecem melhores infraestruturas apenas para o EM pode induzir e acirrar as desigualdades educacionais a depender do tipo de rede de escolas que os estudantes brasileiros frequentam, principalmente se considerarmos as trajetórias de estudantes que, por exemplo, cursam a educação básica toda na rede estadual de ensino. 
Tabela 6 - Percentuais de escolas nos níveis da escala de infraestrutura escolar, por depêndencia administrativa e segmento de ensino

\begin{tabular}{|c|c|c|c|c|c|c|c|c|c|c|c|c|}
\hline \multirow{3}{*}{$\begin{array}{l}\text { Dependência } \\
\text { administrativa }\end{array}$} & \multicolumn{12}{|c|}{ Níveis de infraestrutura escolar } \\
\hline & \multicolumn{3}{|c|}{ Elementar } & \multicolumn{3}{|c|}{ Básica } & \multicolumn{3}{|c|}{ Adequada } & \multicolumn{3}{|c|}{ Avançada } \\
\hline & $\mathrm{El}$ & $\mathrm{EF}$ & EM & El & $\mathrm{EF}$ & EM & $\mathrm{El}$ & EF & EM & $\mathrm{El}$ & EF & EM \\
\hline Federal & $0,00 \%$ & $0,00 \%$ & $0,00 \%$ & $0,00 \%$ & $0,00 \%$ & $0,01 \%$ & $0,00 \%$ & $0,02 \%$ & $0,38 \%$ & $0,01 \%$ & $0,03 \%$ & $0,13 \%$ \\
\hline Estadual & $0,19 \%$ & $0,14 \%$ & $1,97 \%$ & $0,30 \%$ & $2,38 \%$ & $24,31 \%$ & $0,36 \%$ & $14,57 \%$ & $39,94 \%$ & $0,11 \%$ & $0,32 \%$ & $0,43 \%$ \\
\hline Municipal & $22,54 \%$ & $2,93 \%$ & $0,06 \%$ & $28,41 \%$ & $37,99 \%$ & $0,91 \%$ & $19,61 \%$ & $19,08 \%$ & $0,64 \%$ & $1,72 \%$ & $0,08 \%$ & $0,02 \%$ \\
\hline Privada & $0,14 \%$ & $0,00 \%$ & $0,02 \%$ & 7,69\% & $5,68 \%$ & $9,40 \%$ & $15,75 \%$ & $15,89 \%$ & $20,27 \%$ & $3,15 \%$ & $0,89 \%$ & $1,52 \%$ \\
\hline Brasil & $22,88 \%$ & $3,07 \%$ & $2,05 \%$ & $36,40 \%$ & $46,06 \%$ & $34,63 \%$ & $35,73 \%$ & $49,56 \%$ & $61,22 \%$ & $4,99 \%$ & $1,32 \%$ & $2,10 \%$ \\
\hline
\end{tabular}

Fonte: Elaboração da autora.

A Tabela 7 apresenta detalhadamente a distribuição das escolas nas escalas da El, do EF e do EM, em relação à sua localização, ou seja, se são urbanas ou rurais. Observa-se, ainda, o inexpressivo percentual de escolas rurais posicionadas nos níveis adequado e avançado das escalas para todos os segmentos de ensino analisados. Nota-se uma concentração dessas escolas nos níveis mais baixos das escalas em todos os segmentos de ensino, destacando-se a El, com 22,46\% no nível elementar, e o EF, com 35,10\% no nível básico.

Tabela 7 - Percentuais de escolas nos níveis da escala de infraestrutura escolar, por localização e segmento de ensino

\begin{tabular}{|c|c|c|c|c|c|c|c|c|c|c|c|c|}
\hline \multirow{3}{*}{ Localização } & \multicolumn{12}{|c|}{ Níveis de infraestrutura escolar } \\
\hline & \multicolumn{3}{|c|}{ Elementar } & \multicolumn{3}{|c|}{ Básica } & \multicolumn{3}{|c|}{ Adequada } & \multicolumn{3}{|c|}{ Avançada } \\
\hline & $\mathrm{El}$ & $\mathrm{EF}$ & EM & El & $\mathrm{EF}$ & EM & $\mathrm{El}$ & $\mathrm{EF}$ & EM & El & $\mathrm{EF}$ & EM \\
\hline Urbana & $0,41 \%$ & $0,01 \%$ & $0,62 \%$ & $14,42 \%$ & $10,96 \%$ & $28,40 \%$ & $30,62 \%$ & $43,36 \%$ & $59,26 \%$ & $4,92 \%$ & $1,31 \%$ & $2,07 \%$ \\
\hline Rural & $22,46 \%$ & $3,06 \%$ & $1,43 \%$ & $21,98 \%$ & $35,10 \%$ & $6,23 \%$ & $5,11 \%$ & $6,20 \%$ & $1,96 \%$ & $0,07 \%$ & $0,01 \%$ & $0,02 \%$ \\
\hline Brasil & $22,88 \%$ & $3,07 \%$ & $2,05 \%$ & $36,40 \%$ & $46,06 \%$ & $34,63 \%$ & $35,73 \%$ & $49,56 \%$ & $61,22 \%$ & $4,99 \%$ & $1,32 \%$ & $2,10 \%$ \\
\hline
\end{tabular}

Fonte: Elaboração da autora. 


\section{CONCLUSÕES}

A presente pesquisa apresenta-se como uma inovação para a área de construção de medidas no cenário nacional, pois, além de fazer uso de uma metodologia moderna de análise a TRI para MRG, estabeleceu três escalas de infraestrutura escolar com quatro níveis que conseguem precisar, além da existência, a qualidade ou a quantidade de determinados itens nos contextos escolares para cada um dos segmentos de ensino da educação básica. Essas informações podem subsidiar um direcionamento equitativo dos recursos públicos, priorizando, por exemplo, aquelas escolas que não contam com a infraestrutura básica e pedagógica.

Além disso, pode influenciar no desenvolvimento de estratégias que viabilizem a adequação e a revitalização da infraestrutura escolar que seja capaz de ofertar condições de implementação do currículo mínimo, garantido pela BNCC, de modo a apontar, ainda, que a falta de uma infraestrutura adequada das escolas brasileiras pode ser determinante para o aumento das desigualdades educacionais no país impeditiva para implementação de um currículo nacional. Assim, faz-se necessário considerar como meta que todas as escolas da educação básica sejam posicionadas por esses indicadores no nível adequado das escalas que, por sua vez, sumariza os elementos fundamentais para o processo de ensino-aprendizagem de cada uma das etapas de ensino, estabelecendo-se este como o patamar mínimo de infraestrutura para a El, o EF e o EM.

Contudo, este estudo apresenta como limitação a falta de um tratamento específico para variáveis relacionadas ao porte e à localização das escolas, na composição desses indicadores. Pesquisas futuras devem levar em consideração essas variáveis, verificando se de fato a ponderação delas na construção das medidas pode estar influenciando nos parâmetros de discriminação e de dificuldade das alternativas dos itens, em especial para a definição dos níveis avançados das escalas. Continua também sendo uma das limitações do indicador a quantidade de itens utilizada para a construção da escala, pois, quanto maior for, maior será a precisão das medidas e a confiabilidade das informações disponibilizadas.

Salienta-se que essas escalas não são comparáveis e que, como avaliam a qualidade ou quantidade de alguns dos itens que compõem a medida, ainda serão necessárias descrições mais específicas e detalhadas entre os intervalos, e não apenas entre os níveis, considerando ainda a existência ou não das cinco dimensões operacionais que compreendem o conceito infraestru- 
tura escolar. A proposta feita nesta pesquisa é apenas a primeira a adotar o MRG, mostrando que ainda cabem aprimoramentos para o indicador. Dessas lacunas, advém a necessidade de mais estudos e instrumentos que abordem as definições constitutivas e operacionais, abarcando todas as dimensões do traço latente observado.

\section{REFERÊNCIAS}

ALBANEZ, A.; FERREIRA, F.; FRANCO, F. Qualidade e equidade no ensino fundamental brasileiro. Pesquisa e Planejamento Econômico, v. 32, n. 3, p. 453475, dez. 2002.

ANDRADE, M. et al. Gênero e desempenho em matemática ao final do ensino médio: quais as relações? Estudos em Avaliação Educacional, São Paulo, v. 27, p. 77-95, jan./jun. 2003.

BAKER, F. The basics of item response theory. ERIC Clearinghouse on Assessment and Evaluation, University of Wisconsin, 2001.

BEATON, A. E.; ALLEN, N. L. Interpreting scales through scale anchoring. Journal of Educational Statistics, v. 17, p. 191-204, 1992.

BRASIL. Ministério da Educação. Instituto Nacional de Estudos e Pesquisas Educacionais Anísio Teixeira. Secretaria de Educação das Unidades de Federação. Censo Escolar 2017. Brasília: MEC, 2018.

CASTRO, E. S. Análise da validade dos indicadores de infraestrutura escola brasileira. Estudo em andamento, na composição da tese. 2018

Estudo do resultado na Prova Brasil de 2011 das escolas com estudantes beneficiários do programa bolsa família. Brasília, 2014. 120 f. Dissertação (Mestrado em Desenvolvimento, Sociedade e Cooperação Internacional) - Centro de Estudos Avançados Multidisciplinares, Universidade de Brasília, 2014.

CASTRO, E. S. et al. A série histórica da infraestrutura escolar brasileira. Estudo em andamento, na composição da tese. 2018

KARINO, C. A. Avaliação da igualdade, equidade e eficácia no sistema educacional brasileiro. 2016. 147 f. Tese (Doutorado em Psicologia Social, do Trabalho e das Organizações) - Universidade de Brasília. Brasília, 2016. 
KOWALTOWSKI, D. Arquitetura escolar: o projeto do ambiente de ensino. São Paulo: Oficina de Textos, 2011.

NETO, J. J. S. et al. Uma escala para medir a infraestrutura escolar. Estudos em Avaliação Educacional, São Paulo, v. 24, n. 54, p. 78-99, jan./abr. 2013.

REYNOLDS, D. et al. Educational Effectiveness Research (EER): a state-of-the-art review. School Effectiveness and School Improvement: An International Journal of Research, Policy and Practice, v. 25, n. 2, p. 197-230, 2014.

SAMEJIMA, F. A. Estimation of latent ability using a response pattern of graded scores. Psychometrika, v. 35, n. 1, p. 139, mar. 1970.

SAMMONS, P. et al. Key characteristics of effective schools: a review of school effectiveness research. London: Office for Standards in Education [OFSTED], 1995.

SASTRE, J. R. de S. O edifício escolar nas políticas públicas de educação: Rio Grande do Sul 1999-2006. 2010. 472 f. Tese (Doutorado em Educação) Universidade Federal do Rio Grande do Sul, Porto Alegre, 2010.

SOARES, J. F. O efeito da escola no desempenho cognitivo de seus alunos. Revista Electronica Iberoamericana sobre Calidad, Eficacia y Cambio en Educación, v. 2, n. 2, p. 83-104, jul./dez. 2004.

SOARES, J. F.; ALVES, M. T. G. Desigualdades raciais no sistema brasileiro de educação básica. Educação e Pesquisa, v. 29, n. 1, p. 147-165, jan./jun. 2003.

SOARES, J. F.; ANDRADE, R. J. Nível socioeconômico, qualidade e equidade das escolas de Belo Horizonte. Ensaio: Avaliação de Políticas Públicas Educacionais, v. 14, n. 50, p. 107-126, jan./mar. 2006.

Recebido em: 15 de dezembro de 2019

Aceito em: 15 de junho de 2020

Publicado em: 30 de junho de 2020 